\title{
Recomendaciones para el manejo de mordeduras ocasionadas por animales
}

Recibido: 22-09-05 Aceptado: 09-12-05

Correspondencia a: Leonor Jofré Morales leonorjofre@gmail.com

\begin{abstract}
Leonor Jofré M., Cecilia Perret P., Katia Abarca V., Verónica Solari G., Roberto Olivares C. y Javier López Del P., en representación del Comité de Infecciones Emergentes, Sociedad Chilena de Infectología
\end{abstract}

\section{Guidelines for management of animal bites}

Bites caused by pets or free living animal, including the so called exotic ones are a common cause of medical care request, although its real dimension has not been well defined in the local setting. This paper reviews the epidemiology of the topic placing emphasis in the initial approach and recomendations for the management of dog and cat bites. Due to increasing ownership or contact with other animals, management of bites from hamsters, mice, ferrets, rabbits, prairie dogs, monkeys, bats, lizards and bird bites is also discussed.

Key words: Bite wounds, animal bites, mammalian bite, dog bite, cat bite, pets bites.

Palabras claves: Mordeduras, mordedura por animales, mordedura por mamíferos, mordedura por perro, mordedura por gato, mordeduras por mascotas.

\section{Introducción}

$\mathrm{L}$ as mordeduras ocasionadas por animales son accidentes más frecuentes de lo que se cree, en E.U.A se estima que una de cada dos personas es mordida por un animal o por una persona, agresiones que generan $\sim 1 \%$ de las atenciones en los Servicios de Emergencia, de las cuales 10 a $15 \%$ deben ser suturadas y $1 \%$ de los pacientes es hospitalizado por

\begin{tabular}{|c|c|c|c|c|}
\hline \multirow[t]{2}{*}{ Servicio de Salud } & \multicolumn{2}{|c|}{ 2004* } & \multicolumn{2}{|c|}{$2005^{* *}$} \\
\hline & $\mathbf{n}$ & (\%) & $\mathbf{n}$ & (\%) \\
\hline Metropolitano Norte & 880 & $(11,0)$ & 854 & $(12,4)$ \\
\hline Metropolitano Sur & 2.386 & $(29,6)$ & 1.991 & $(28,7)$ \\
\hline Metropolitano Occidente & 1.453 & $(18,0)$ & 1.188 & $(17,0)$ \\
\hline Metropolitano Oriente & 1.349 & $(16,7)$ & 1.087 & $(15,7)$ \\
\hline Metropolitano Sur-Oriente & 971 & $(12,0)$ & 884 & $(12,7)$ \\
\hline Metropolitano Central & 1.020 & $(12,6)$ & 922 & $(13,3)$ \\
\hline Total RM & 8.059 & $(100)$ & 6.926 & $(100)$ \\
\hline $\begin{array}{l}\text { * Tasa RM año 2004: 127/100.000 hbtes } \\
\text { ** Tasa RM año 2005: 106/100.000 hbtes } \\
\text { Fuente DEIS- Ministerio de Salud de Chile }\end{array}$ & & & & \\
\hline
\end{tabular}

esta causa ${ }^{1,2}$. En Santiago de Chile, Región Metropolitana (RM), se generó un total de 6.926 consultas por mordeduras en el primer semestre del 2005, con una disminución de $14 \%$ con respecto al año 2004, en que se registraron 8.059 accidentes de esta naturaleza. (Tabla 1).

La población de mascotas en E.U.A. ha aumentado en forma considerable alcanzando a alrededor de 50 millones de perros. Esta cantidad de animales aumenta la probabilidad de sufrir una mordedura por alguno de ellos, y afectará en forma especial a los niños ${ }^{3}$. En Santiago, se estima que existe una población de 900.000 caninos y 350.000 felinos, con un índice promedio de tenencia de 1 perro por cada 5,4 habitantes y 1 gato por cada 14 habitantes ${ }^{4}$.

Diversos estudios se han publicado sobre mordeduras enfocando los factores de riesgo, gravedad, sus complicaciones infecciosas y la indicación de antimicrobianos; a pesar de esto, el manejo de algunas mordeduras sigue siendo controversial ${ }^{5,6}$.

Este documento aborda las mordeduras más frecuentes producidas por animales incluyendo las mascotas.

\section{Mordeduras ocasionadas por perros}

Epidemiología. La mordedura causada por perro es la más frecuente entre todas las agresiones producidas por animales, correspondiendo al $90 \%$ de ellas. 
En E.U.A. se calcula que ocurren alrededor de 4,7 millones de episodios al año, 800.000 de los cuales requirieron de atención médica. La verdadera incidencia es desconocida por una subnotificación del accidente, no todos los pacientes consultan en un servicio de emergencia y la mayoría son manejados en el hogar, situación que correspondería al doble de los que se atienden en servicios de emergencia ${ }^{1,3}$. Este accidente es más frecuente en los dueños de mascotas, ocasionada por las propias mascotas más que por perros vagabundos y mayoritariamente afecta a niños más que a adultos $(26 \text { versus } 12 \%)^{7}$. Los niños son más afectados por su menor tamaño corporal, mayor frecuencia de acciones/conductas que pueden motivar ataques por parte del animal y la relativa dificultad para escapar si son atacados. La edad de mayor ocurrencia es entre 5 y 9 años, grupo etario que presenta con mayor frecuencia un síndrome post traumático; hasta $55 \%$ de los niños seguidos post accidente lo pueden presentar y aún estar presente hasta 1 mes más tarde 8 .

La importancia de estas mordeduras está enfocada a la posibilidad de adquirir rabia, enfermedad mortal que puede ser prevenida a través de una oportuna profilaxis post exposición (PPE) ${ }^{9}$.

Manejo inicial. Sufrido el accidente el paciente debe ser estabilizado primero, posteriormente se realizará una anamnesis dirigida a descartar cofactores de mayor riesgo para desarrollar una infección bacteriana como diabetes mellitus, estados de inmunocompromiso, alteraciones cutáneas de la zona afectada, hipo o asplenias funcionales o anatómicas, mesenquimopatías e insuficiencia hepática, entre otras ${ }^{10}$.

Se debe consignar el tipo de accidente, motivo del ataque y si fue realizado por un perro identificable o vagabundo; en el primer caso preguntar por el estado de vacunación anti-rábica y los controles veterinarios.

Al afectado siempre se le debe preguntar por su esquema de vacunación anti-tetánica. En nuestro país se incorporó al PAI la vacunación anti-tetánica durante 1975. Quienes tienen sobre 30 años probablemente no han sido vacunados y deben recibir esta vacuna en esquema de tres dosis: 2 dosis separadas por 1 a 2 meses y la tercera 6 a 12 meses después. Quienes tienen menos de 30 años han sido inmunizados hasta los 7 años de edad (primer año básico de enseñanza escolar), esquema que otorga protección segura durante 10 años (en general hasta los 17 años de edad); sobre esa edad debe indicarse vacunación complementaria con 1 dosis de refuerzo de toxoide tetánico (en la práctica toxoides dT).

La herida debe ser lavada con abundante agua o solución salina fisiológica $(\mathrm{NaCl} 9 \%$ ) estéril, en caso de necrosis es imprescindible debridar y asear cuida- dosamente, clasificar el tipo de herida y su extensión $\mathrm{y}$, de sospecharse un compromiso articular u óseo, efectuar radiografías.

Este tipo de herida en general no se sutura, a menos que se ubique en la cara y tenga menos de 8 horas de evolución. Las heridas profundas, lacerantes, localizadas en la mano, con más de 8 horas de evolución, y en pacientes con factores de riesgo, tienen una mayor probabilidad de infectarse, con una frecuencia que va entre 15 y $20 \%{ }^{11,12}$.

Constituyen indicaciones de hospitalización: herida con compromiso de tendones o articulaciones, la presencia de manifestaciones sistémicas, lesiones que requieran cirugía reparadora, celulitis graves, heridas en pacientes inmunocomprometidos y fracaso del tratamiento antimicrobiano oral ${ }^{13}$.

Estos accidentes son de notificación obligatoria, existiendo un formulario especial que se encuentra disponible en las Secretarias Regionales Ministeriales (SEREMI) de Salud.

Microbiología. La mayoría de las infecciones tienen una etiología polimicrobiana. Los agentes aerobios aislados con mayor frecuencia son: Pasteurella multocida y Staphylococcus aureus. Pueden encontrarse Pasteurella septica, Pasteurella canis, que se recuperó en un estudio en $18 \%$ de las mordeduras infectadas, Pasteurella dagmatis, Streptococcus sp, Moraxella sp, Neisseria sp, Corynebacterium sp, Eikenella corrodens, Capnocytophaga canimorsus, Bergeyella zoohelcum y bacterias NO-1. Entre los agentes anaeróbicos estrictos se encuentran Bacteroides fragilis, Fusobacterium sp y Veillonella parvula ${ }^{14-18}$.

Pasteurella multocida es un cocobacilo gramnegativo que forma parte de la microbiota oral de perros y gatos, se encuentra en 25 a $50 \%$ de los perros y en 70 a $90 \%$ de los gatos y se ha aislado hasta en $25 \%$ de las mordeduras infectadas ocasionadas por perros. Provoca una intensa respuesta inflamatoria con dolor y aumento de volumen en las primeras 24 a 48 horas de ocurrido el accidente, con celulitis localizada que puede evolucionar hacia la formación de absceso, fiebre, adenopatías regionales y linfangitis en $\sim 70 \%$ de los casos. Las complicaciones descritas son artritis séptica, osteomielitis, septicemia, meningitis, endocarditis, peritonitis y neumonía; en heridas cercanas a articulaciones y huesos siempre deben descartarse una artritis séptica, tenosinovitis u osteomielitis ${ }^{19,20}$. P. multocida es sensible a bencilpenicilina, cefalosporinas de tercera generación, cloranfenicol y tetraciclina, presenta resistencia a cloxacilina, cefalosporinas de primera generación, eritromicina y clindamicina ${ }^{21}$.

Capnocytophaga canimorsus es un bacilo gram- 
negativo fastidioso de crecimiento lento que también forma parte de la microbiota oral de perros y gatos. Produce infección en pacientes asplénicos, con insuficiencia hepática o inmunodeficiencias. En estos pacientes se ha descrito un cuadro septicémico de evolución rápidamente progresiva, similar a una meningococcemia; puede producir además endocarditis o meningitis ${ }^{22-24}$. El tratamiento de elección es penicilina, siendo además susceptible a clindamicina, cefalosporinas de tercera generación, cloranfenicol, rifampicina, doxiciclina, vancomicina, imipenem y quinolonas. No se ha reportado la presencia de $\beta$-lactamasas y la resistencia a quinolonas es inusual ${ }^{25}$. Capnocytophaga cynodegmi también es encontrada en la microbiota oral del perro. Se relaciona a infecciones de piel y tejidos blandos, se aisló en un cuadro de bacteriemia, celulitis y neumonía en un paciente diabético, y en una meningitis con purpura fulminans en una paciente esplenectomizada ${ }^{26}$.

Bergeyella zoohelcum (llamada previamente Weeksella zoohelcum) es un bacilo gramnegativo encontrado en la microbiota bucal residente del perro. Se ha aislado a partir de abscesos, tenosinovitis, septicemia, meningitis, endocarditis y neumonía. Es susceptible a $\beta$-lactámicos, fluoroquinolonas y cloranfenicol y tiene una susceptibilidad variable a cotrimoxazol y tetraciclina ${ }^{27}$.

Las bacterias NO-1 (non oxidizer group 1) son bacterias recientemente relacionadas a mordeduras producidas por perros y gatos, que causan infecciones localizadas. Los pacientes han sido tratados con cloxacilina y una combinación de antimicrobianos como amoxicilina, ceftriaxona, cefazolina y penicilina ${ }^{28-29}$.

Neisseria weaveri y Neisseria canis se asocian a infecciones respiratorias en pacientes con bronquiec$\operatorname{tasias}^{30-32}$.

Profilaxis antimicrobiana. La antibioprofilaxis no está indicada en todos los casos, en heridas limpias y superficiales sólo se recomienda controlar su evolución. Hay pocos estudios evaluando el uso de antibacterianos profilácticos, en un meta-análisis del uso de amoxicilina/ácido clavulánico se encontró que el riesgo relativo de infección con el uso de este antimicrobiano fue de 0,56 (IC 95\% 0,38-0,82) ${ }^{33}$. En una revisión de Cochrane Library que comprendió ocho trabajos randomizados, comparando antibioprofilaxis versus placebo o no intervención, se concluyó que el régimen profiláctico no parece disminuir la tasa de infección en mordeduras causadas por perros o gatos, y que el tipo de heridas, ya sea punción o laceración, no tiene influencia en la eficacia de la profilaxis. Sin embargo, se encontró una diferencia estadísticamente significativa en la disminución de la tasa de infección en mordeduras localizadas en las inferidas por huma$\operatorname{nos}^{34}$.

La profilaxis está indicada en presencia de heridas profundas, localizadas en mano y en aquellas que requieren cirugía ${ }^{35}$. De acuerdo a los hallazgos microbiológicos el tratamiento de estas mordeduras debe ser dirigido a agentes tanto aerobios como anaerobios estrictos y que incluya $P$. multocida, por lo que se recomienda el uso de amoxicilina/ácido clavulánico para una amplia cobertura de estos agentes, por un plazo de 3 a 5 días, dependiendo de las condiciones y evolución de la herida; en caso de una celulitis debe tratarse por un plazo de 10 a 14 días $^{9-10,35}$. En pacientes alérgicos a penicilina puede usarse clindamicina, que cubre a anaerobios estrictos, C. canimorsus, Streptococcus sp, $S$. intermedius y $S$. aureus, pero no a $P$. multocida, así que debe asociarse a cotrimoxazol, que incluye a $P$. multocida y E. corrodens. Doxiciclina puede ser indicada en niños a contar de los 8 años de edad y en mujeres no embarazadas. El uso de macrólidos está limitado por la resistencia de $P$. multocida, que tiene $\sim 20 \%$ de susceptibilidad a estos antimicrobianos ${ }^{36}$. Otra alternativa de manejo es ceftriaxona en uso intramuscular ${ }^{10}$. Se debe hospitalizar a los pacientes que tengan una infección causada por Pasteurella que presenten fiebre, calofríos, celulitis rápidamente progresiva y lesiones con compromiso articular, tendíneo y óseo ${ }^{6}$.

Siempre debe preguntarse por los antecedentes de contactos o mordeduras producidas por perros en pacientes con cuadros graves de origen no precisado, especialmente si son hipo o asplénicos, inmunodeficientes o insuficientes hepáticos y se debe solicitar la búsqueda de agentes fastidiosos o de desarrollo lento al laboratorio de microbiología ${ }^{1,36-37}$.

Profilaxis de rabia. El último caso de rabia humana transmitido por la mordedura de un perro en nuestro país se registró en el año $1975^{38}$. Como se expone más adelante, los murciélagos insectívoros han pasado a representar el principal reservorio del virus en el país con transmisión al humano ${ }^{39}$.

Vacunación anti-rábica. La profilaxis pre-exposición de rabia está indicada a personas con alto riesgo de adquisición, como el personal de laboratorio que trabaja en la elaboración de vacunas anti-rábicas, en áreas de diagnóstico e investigación del virus rábico, en personal veterinario, manipuladores de animales y en viajeros a zonas endémicas (Tabla 2).

En el manejo profiláctico de heridas post exposición (PPE) se debe realizar un lavado profundo de la herida con agua corriente y jabón (que por su efecto detergente destruye el manto lipídico del virus) y aplicación 
de un desinfectante. La conducta a seguir en relación a vacunación anti-rábica dependerá de factores como localización de la herida y su profundidad, las características del animal (observable o no, con vacuna antirábica vigente o no), circunstancias de la mordedura (provocada o no) y la historia de vacunación antirábica previa del sujeto mordido.

Si el perro es ubicado y se acredita que cuenta con su esquema de vacunación anti-rábica al día, que incluye una primera dosis al tercer mes de vida, una segunda dosis 6 a 12 meses después y revacunación anual (cada dos años con las nuevas vacunas), está indicado solamente la observación del animal. Si llegara a presentar un comportamiento inusual como cambio en la conducta (excitación, agresividad, inquietud), fotofobia, dificultad para tragar, temblores, alteración motora, postración o muerte, el animal debe ser sacrificado, e iniciarse inmediatamente la vacunación de los sujetos expuestos y uso de inmunoglobulina hiperinmune. Sacrificado el animal, se empacará su cabeza en hielo y enviará a estudio al Laboratorio de Referencia Nacional para Rabia, del Instituto de Salud Pública (ISP).

En los casos que el perro no tiene las vacunas al día pero es ubicado, debe igualmente observarse. Si se es mordido por un perro no ubicable, se deberá tomar en cuenta el antecedente de "provocación", según se indica en la Tabla 3, que establece la Norma de Vacunación Post Exposición del MINSAL en Chile.

La vacuna en uso actualmente contiene virus rabia inactivado que ha sido cultivada en líneas celulares o en cultivo de embrión de pato. Se indican 5 dosis en total: al día $0,3,7,14$ y 28 por vía intramuscular en la región deltoidea o en la cara anterior externa del muslo. Existe un esquema rápido alternativo, que no es aplicado en nuestro país, con 4 dosis: 2 dosis en el día 0 en lugares diferentes, una dosis el día 7 y otra el día 21, indicado en pacientes que consultan después de los 10 días de ocurrido el accidente y en casos ocasionados por un animal sospechoso de rabia.

En personas previamente vacunadas se indica la vacunación anti-rábica de acuerdo a esquema (Tabla 4). En la RM de Chile, en el primer semestre del año 2005 se ha indicado un total de 1.886 esquemas de PPE anti-rábica (Fuente DEIS-MINSAL).

Inmunoglobulina anti-rábica. Puede ser de origen humano ("suero homólogo") o equino ("suero heterólogo"), su uso se reserva para aquellas personas que fueron expuestas a animales probablemente rabiosos y que no fueron vacunadas dentro de los 10 primeros días post exposición, en grandes mordeduras y alta sospecha de animal rabioso, indicación que está sujeta a consulta con el encargado del PAI o al epidemiólogo de la SEREMI de Salud correspondiente, quien solicitará la inmunoglobulina al stock crítico del Hospital de Urgencia de la Asistencia Pública de Santiago, donde se encuentra disponible. Presentación: frascos de $2 \mathrm{ml}$ de suero homólogo (300 UI). Se indica una dosis de $20 \mathrm{UI} / \mathrm{kg}$ de peso en el caso de la inmunoglobulina homóloga y de $40 \mathrm{UI} / \mathrm{kg}(0,2 \mathrm{ml} / \mathrm{kg}) \mathrm{si}$ es inmunoglobulina heteróloga, esta última no se encuentra en nuestro país. Debe aplicarse infiltrando cuidadosamente en la profundidad de la herida y alrededor de ella ${ }^{40-42}$. Los sujetos con vacunación previa no requieren de la administración de inmunoglobulina.

\begin{tabular}{|l|}
\hline Tabla 2. Vacunación anti-rábica pre-exposición \\
\hline Indicación de profilaxis pre-exposición: \\
\hline - Médicos Veterinarios \\
- Personal de laboratorio que trabaje con virus rabia \\
- Cuidadores de animales \\
- Guardias de caza y cazadores \\
- Visitantes a zonas de alta endemia y con riesgo de exposición \\
Esquema de vacunación: \\
- Días 0 - 7 y 28 \\
- Rrimer refuerzo al año \\
\hline Se emacunación cada 3 años \\
\hline
\end{tabular}

Prevención. Se ha trabajado en guías anticipatorias de prevención de mordeduras causadas por perros. Entre las medidas sugeridas destaca elegir como mascotas los perros no agresivos, mantener estos animales en espacios adecuados y sacarlos a pasear diariamente. Se le debe enseñar una conducta de sumisión más que de agresividad. Debe educarse a los niños para que no molesten a sus mascotas cuando comen, duermen o cuidan de sus cachorros. Es recomendable que los niños no jueguen con los perros sin la adecuada supervisión de un adulto, eviten el contacto directo del animal con la cara del niño, no jueguen con perros vagabundos y avisen a un adulto en caso de observar conductas extrañas en las mascotas ${ }^{43}$. La medida profiláctica más importante es la vacunación anti-rábica de la mascota.

\section{Mordeduras ocasionadas por gatos}

Las mordeduras causadas por gatos siguen en frecuencia a las producidas por perros, representan entre 3 y $15 \%$ de todas las mordeduras ocasionadas por 


\section{Tabla 3. Indicación de vacunación e inmunoglobulina anti-rábicas post exposición en Chile}

\begin{tabular}{|c|c|c|c|}
\hline Tipo de animal & Conducta con el animal & Vacunación & Uso de inmunoglobulina \\
\hline \multirow[t]{4}{*}{ Perro - Gato } & Ubicable: observar 10 días & No vacunar, hasta tener resultado de la observación & $\begin{array}{l}\text { Sólo si el animal presenta } \\
\text { síntomas }\end{array}$ \\
\hline & No ubicable: animal no provocado & Vacunar según esquema & No \\
\hline & No ubicable: animal provocado 2 & No vacunar & No \\
\hline & $\begin{array}{l}\text { Animal muerto: enviar de inmediato (cabeza) } \\
\text { al ISP para estudio }\end{array}$ & No vacunar, decidir según resultado del estudio ${ }^{3}$ & Esperar resultado del estudio \\
\hline \multirow[t]{2}{*}{ Murciélago } & $\begin{array}{l}\text { Si es posible, enviar de inmediato al ISP } \\
\text { para su estudio }\end{array}$ & No vacunar hasta tener resultado del estudio & No \\
\hline & No ubicable & Vacunar según esquema & No \\
\hline \multirow[t]{2}{*}{$\begin{array}{l}\text { Carnívoros silvestres: } \\
\text { zorro, hurón, puma, } \\
\text { mono }\end{array}$} & $\begin{array}{l}\text { Si es posible, enviar animal (cabeza) al ISP } \\
\text { para su estudio }\end{array}$ & No vacunar, decidir según resultado del estudio & $\begin{array}{l}\text { Esperar resultado del estudio } \\
\text { Uso depende del resultado y } \\
\text { características de la } \\
\text { mordedura }\end{array}$ \\
\hline & No ubicable & Vacunar según esquema & No \\
\hline $\begin{array}{l}\text { Animales de abasto: } \\
\text { vacunos y equinos }\end{array}$ & $\begin{array}{l}\text { No vacunar a menos que la situación } \\
\text { epidemiológica sea extraordinaria }{ }^{4}\end{array}$ & No & No \\
\hline $\begin{array}{l}\text { Roedores y lagomorfos: } \\
\text { ratas, ratones, conejos, } \\
\text { liebres, cuyes }\end{array}$ & $\begin{array}{l}\text { No vacunar a menos que la situación } \\
\text { epidemiológica sea extraordinaria }\end{array}$ & No & No \\
\hline $\begin{array}{l}\text { ISP: Instituto de Salud PL } \\
\text { 1. La vacunación post ex } \\
\text { 2. Tomar en consideraci } \\
\text { la duda: vacunar. } \\
\text { 3. Si el estudio demora } \\
\text { el resultado del estud } \\
\text { 4. Detección de circulaci } \\
\text { accidente. Si la perso }\end{array}$ & $\begin{array}{l}\text { blica: Av. Maratón } 1000 \text { - Nuñoa- Santiago. ( } 5 \\
\text { posición se realiza en forma gratuita en los ser } \\
\text { on la provocación. Si existe seguridad que el at } \\
7 \text { días o más, citar para iniciar el tratamiento. S } \\
\text { o, los casos positivos se informan de inmediato } \\
\text { ón del virus rábico a través de la vigilancia de r } \\
\text { ha tiene antecedentes de inmunización incompl }\end{array}$ & $\begin{array}{l}\text { 2)-350 } 7477 \text { / } 3507411 \text { (directo) } \\
\text { os de atención de salud. } \\
\text { ue fue provocado: no vacunar. Si existen casos de rabi } \\
\text { resultado es negativo, suspender el tratamiento. EI ISF } \\
\text { a fax y los casos negativos se envían por correo. } \\
\text { ina que realiza el ISP, en la especie animal involucrada } \\
\text { completar las } 5 \text { dosis en los días correspondientes. }\end{array}$ & $\begin{array}{l}\text { canina en la región o persiste } \\
\text { demora } 3 \text { días hábiles en tener } \\
\text { en la región de ocurrencia del }\end{array}$ \\
\hline
\end{tabular}

\section{Tabla 4. Esquema de vacunación post exposición en personas} vacunadas con anterioridad

- Menos de un año de haber sido vacunada: dos dosis (días 0 y 3)

- Entre uno y cinco años: tres dosis (días 0 - 3 y 7)

- Más de cinco años: esquema completo (días 0 - 3 - 7 -14 y 28)

- Las personas que no hayan completado el esquema de vacunación en exposiciones anteriores, independiente del tiempo que haya transcurrido entre esa exposición y la exposición actual, deben recibir el esquema completo de 5 dosis animales en E.U.A., y en $90 \%$ de los casos la agresión es sobre los mismos dueños ${ }^{44}$.

La mordedura en este caso es producida por dientes largos y aguzados, que pueden penetrar con mayor facilidad la piel y comprometer alguna articulación y llegar al periostio. La incidencia de infección supera al $50 \%$ (duplica la descrita para mordeduras causadas por perros). Es más frecuente en adultos que en niños, con un promedio de edad de 19,5 años, $44 \%$ se ve en personas sobre 40 años. La mayoría de las lesiones se localizan en el brazo, antebrazo y manos ${ }^{1,10}$.

Manejo inicial. Son válidas las mismas consideraciones descritas para el manejo de mordeduras causadas por perros. 
Microbiología. El agente aislado con mayor frecuencia en infecciones secundarias a mordedura por gatos es $P$. multocida, siendo posible encontrarla en $75 \%$ de las heridas ${ }^{45-46}$. Otros agentes infecciosos son similares a los encontrado en mordeduras de perro infectadas, en $60 \%$ se puede aislar tanto aerobios como anaerobios estrictos. Capnocytophaga canimorsus se encuentra en la microbiota oral en $18 \%$ de los gatos; se han descrito casos de infección por este microorganismo asociadas a mordeduras producidas por gatos ${ }^{47}$.

Un agente importante transmitido por las mordeduras o arañazos de gatos es Bartonella henselae. Se ha aislado de la pulpa dental y de la sangre de estos animales ${ }^{48}$ y su transmisión entre gatos sería favorecida por la pulga del gato (Ctenocephalides felis) ${ }^{49}$. La portación es más frecuente en cachorros especialmente callejeros; en Chile se encontró en gatos asintomáticos una prevalencia de bacteriemia en $44 \%$ y anticuerpos séricos en $96 \%$, (Ferrés M. Comunicación personal). La enfermedad por arañazo de gato se presenta en 75 a $85 \%$ de los casos como una lesión localizada en la zona de rasguño o mordedura, se puede acompañar de adenopatía en la región de drenaje correspondiente. En 15 a $25 \%$ se presenta con manifestaciones atípicas como síndrome de Parinaud, síndrome febril prolongado con compromiso hepatoesplénico, osteomielitis de focos múltiples, encefalitis, neuroretinitis y otras. En pacientes inmunocomprometidos se puede presentar como un cuadro febril prolongado, con compromiso endocárdico, peliosis hepática, esplenitis y angiomatosis bacilar, esta última se presenta especialmente en pacientes con $\operatorname{SIDA}^{50}$.

Francisella tularensis es un cocobacilo gramnegativo pleomórfico, puede ser transmitida por gatos infectados en zonas geográficas con prevalencia de esta patología donde los gatos la adquieren comiendo conejos o ratones infectados, son asintomáticos y la pueden transmitir a su vez por una mordedura o arañazo. En el hombre se manifiesta como una forma úlceroglandular, localizada en las extremidades superiores en aproximadamente $80 \%$ de los casos, o como neumonía. Este diagnóstico debe considerarse en pacientes mordidos por gatos que tengan celulitis o neumonía, con aspecto séptico, y que vivan en zonas de endemia ${ }^{51}$.

Yersinia pestis también puede transmitirse por mordedura causadas por gatos en zonas geográficas donde prevalece esta enfermedad; sin embargo, este mecanismo de transmisión es el menos frecuente. El gato infectado, a diferencia de lo que sucede si el animal adquirió $F$. tularensis, se ve comprometido. La forma de presentación más frecuente es la bubónica con predominio de localización axilar, pudiendo complicarse con una neumonía ${ }^{52}$.
En mordeduras ocasionadas por otros felinos como el tigre se encuentra también $P$. multocida, habiéndose descrito nuevas subespecies de este microorganismo ${ }^{53}$.

Profilaxis antimicrobiana. En este tipo de mordeduras está siempre indicada la antibioprofilaxis, por la alta frecuencia de infección y la mayor probabilidad de encontrar P. multocida. El fármaco de elección es amoxicilina/ácido clavulánico por las consideraciones comentadas previamente.

Profilaxis anti-tetánica. Se debe revisar el esquema de inmunización anti-tetánica e indicar refuerzo o esquema completo según sea el caso.

Profilaxis de rabia. No se requiere de profilaxis anti-rábica por la baja frecuencia de ocurrencia en nuestro país, el último caso de rabia en gatos ocurrió el año 2000.

\section{Mordeduras ocasionadas por hámsters}

Epidemiología. Ocasionalmente se recibe una consulta por mordedura causada por hámster, con una frecuencia de $2,5 \%$ en una serie clínica ${ }^{54}$.

Microbiología. Han sido comunicados como complicación de este tipo de mordeduras el compromiso óseo por Acinetobacter $\mathrm{sp}^{55}$ y peritonitis por Pasteurella aerogenes y Pasteurella pneumotropica ${ }^{56-57}$. El hámster puede transmitir el virus de la coriomeningitis linfocitaria (CML), un arenavirus que produce, en la mayoría de los casos, una infección asintomática en el hombre. Se han descrito meningitis aséptica, encefalitis, mielitis transversa, orquitis, parotiditis, miocarditis y neumonía causadas por virus de CML. El recién nacido es altamente vulnerable a esta infección, su adquisición por vía vertical produce compromiso grave de SNC con hidrocefalia y corio-retinitis ${ }^{58-59}$. Los roedores, especialmente ratones y hámsters, son el reservorio natural de esta infección, la adquieren por vía horizontal por contacto con secreciones de otros roedores infectados o por vía transplacentaria. El estado de portación en estos animales es crónico. La seroprevalencia de virus de CML en roedores puede variar de 6,9 a 12,7\%, con un promedio de $9,4 \%$ según un estudio de seroprevalencia en Mus domesticus recientemente efectuado en Río Cuarto, Argentina, y varía según la época del año siendo mayor en el verano. En humanos se ha encontrado una seroprevalencia para virus de CML de alrededor de $5 \%{ }^{60}$. El virus puede ser transmitido al hombre por contaminación de alimentos con secreciones como orina, deposiciones, 
saliva o producto de mordeduras por animales infectados. Las personas que trabajan en laboratorios con hámsters tienen mayor riesgo de adquirir la infección ${ }^{61}$.

Manejo. Las medidas de prevención incluyen el lavado de manos cada vez que se manipule o limpie la jaula, no besar o acercarse a la cara del roedor, supervisar a los niños cuando se acercan o manipulan la jaula, insistiendo en el lavado de manos, y evitar que las mascotas entren en contacto con roedores salvajes. Las mujeres embarazadas, durante toda la gestación, y los pacientes inmunocomprometidos, deben evitar el contacto con roedores salvajes y abstenerse de manipular las jaulas de estas mascotas ${ }^{62}$.

La mordedura producida por hámster tiene riesgo de tétanos pero no de rabia. Esta mordedura puede producir reacciones anafilácticas graves, en Japón se han descrito varios casos; el alergeno responsable de esta reacción se encuentra en la saliva del animal y está en etapa de identificación ${ }^{63-64}$.

\section{Mordeduras ocasionadas por ratas y ratones}

Epidemiología. Las ratas y ratones transmiten varios agentes infecciosos que tienen un enorme impacto en salud pública. Este tipo de mordedura es subnotificada; estimaciones del CDC de Atlanta, proyectan en grandes áreas urbanas una frecuencia de 10 personas mordidas al año por cada 100.000 habitantes, por lo que se debería esperar encontrar en ese país entre 3.000 a 4.000 mordeduras anuales, lo que en términos numéricos es de gran impacto. Son factores de riesgo para este tipo de accidente las condiciones de extrema pobreza y la corta edad, es más frecuente en niños bajo 5 años de edad, los que generalmente son mordidos mientras duermen en la noche; en estas circunstancias las mordeduras se ubican por lo general en cara y brazos ${ }^{65}$.

Microbiología. La infección secundaria a estas mordeduras es inhabitual. La incidencia encontrada en un estudio prospectivo realizado en 50 pacientes fue de $2 \%$; el agente aislado en $43 \%$ de los casos fue Staphylococcus epidermidis, también se encontraron Bacillus subtilis, bacilos difteroides y Streptococcus $\alpha$-hemolítico, sin clara trascendencia clínica ${ }^{65}$.

Manejo. El cuidado de la herida consiste en aseo e irrigación con solución salina fisiológica estéril, no se recomienda la antibioprofilaxis por la baja incidencia de infección.

Infección por hantavirus. La presencia de ratones colilargo, Oligoryzomys longicaudatus, y Rattus norvegicus en ambientes peridomiciliarios, obliga a tener en consideración la posible transmisión de hantavirus o virus Seoul, en las áreas geográficas en que han sido descritas estas enfermedades en huma$\operatorname{nos}^{66-67}$.

Fiebre por mordedura de ratas. Cerca de 50 a $100 \%$ de las ratas salvajes y 10 a $100 \%$ de las ratas de laboratorio portan en la nasofaringe Streptobacillus moniliformis, bacilo gramnegativo pleomórfico que requiere de condiciones de microaerofilia y medios especiales para su desarrollo. Este agente puede encontrarse en los dientes y encías de las ratas y es excretado por la orina. Alrededor de $25 \%$ de las ratas porta Spirillum minus, hecho predominante en ratas de Asia y África, en conjuntivas, secreciones corporales y sangre ${ }^{68}$. Ambos agentes están asociados a la fiebre por mordedura de rata. Cerca de $50 \%$ de los casos reportados en E.U.A. ocurre en personal de laboratorio y la otra mitad en niños bajo 12 años de edad.

La fiebre por mordedura de rata se caracteriza por la presencia de fiebre de carácter recurrente acompañada de calofríos, exantema máculo-papular ubicado en extremidades, palma y plantas y poliartralgia de tipo migratoria descrita en $50 \%$ de los casos $^{69}$. La herida generalmente está sana al momento de iniciarse el cuadro febril. El período de incubación varía entre 3 días y 3 semanas. Son complicaciones la neumonía, miocarditis y abscesos en diferentes localizaciones, endocarditis (con mayor frecuencia en pacientes con valvulopatías), puede haber parotiditis, y artritis que lleve al daño permanente de la articulación comprometida. Un $13 \%$ de los casos no tratados ha tenido curso fatal, aunque la mayoría se resuelve espontáneamente en dos semanas ${ }^{70-71}$. La forma espirilar de esta enfermedad (S. minus) se caracteriza por un tener un período de mejoría aparente de la herida, seguido de ulceración, adenopatías regionales, exantema y artritis (ocasional).

La ingestión de alimentos, agua o leche contaminada con S. moniliformis produce la llamada fiebre de Haverhill, que se presenta generalmente como brote epidémico y se manifiesta por la presencia de exantema y artritis.

Se previene la fiebre por mordedura de rata mediante el aseo de la herida con un desinfectante apenas se ha producido el accidente. El tratamiento de elección es bencilpenicilina administrada durante 7 días, seguida de tratamiento oral por 7 a 21 días, dependiendo de la evolución; en algunos casos se ha descrito resistencia a penicilina. En caso de alergia a penicilina puede usarse tetraciclina; existe una limitada experiencia con el uso de eritromicina, clindamicina y ceftriaxona ${ }^{72-73}$. 
Ante la presencia de casos con fiebre y exantema, es muy importante la obtención del dato de tenencia de mascotas y/o de mordedura, con lo que se puede hacer un adecuado diagnóstico y tratamiento.

El riego de transmisión de rabia es bajo, por lo que no es necesario indicar PPE anti-rábica ${ }^{74}$. Debe revisarse la inmunización anti-tetánica y administrarse un refuerzo en caso necesario.

\section{Mordeduras ocasionadas por conejos, ardillas, hurones y perros de la pradera}

Las mordeduras causadas por estos animales son de rara ocurrencia, las heridas son bastante profundas y pueden comprometer articulación y hueso.

Conejos. Pueden transmitir P. multocida y en zonas endémicas se han asociado a la transmisión de $F$. tularensis ${ }^{75}$.

Ardillas. Las mordeduras causadas por ardillas son particularmente infrecuentes y una situación relativamente nueva con la introducción de estos animales a las actividades diarias de los niños. De un total de 2.591 pacientes atendidos por mordeduras durante un periodo de 6 años en E.U.A., 25 de ellas fueron por ardillas (1\%), ninguna se infectó y sólo recibieron antibioprofilaxis 6 de estos pacientes. El 76\% de los accidentes ocurrió mientras alimentaban las ardillas y $25 \%$ al tratar de tomarlas $^{76}$.

No se recomienda el uso de antibioprofilaxis en este tipo de mordeduras por la baja frecuencia de infección. Sí un lavado profuso de la herida y revisión de la inmunización anti-tetánica. Se ha reportado transmisión de Sporotrichosis ${ }^{76}, F$. tularensis, S. moniliformis y $S$. minus $^{77}$. Los conejos y ardillas tienen baja probabilidad de transmitir la rabia ${ }^{78}$.

Hurones. Son mascotas exóticas también de reciente introducción en nuestro medio, en E.U.A. se calcula que en medio millón de hogares hay un hurón. Estos animales pueden atacar en forma inesperada, sin provocación alguna, ocasionando un grave daño especialmente a niños, quienes son los más afectados. La microbiota normal de los hurones no ha sido bien descrita, en un estudio de 3 niños con lesiones faciales ocasionadas por estas mascotas se aisló $S$. aureus en uno de ellos ${ }^{18}$. En el manejo inicial se recomienda observar las medidas generales recomendadas para la atención de todas las mordeduras. Estos animales pueden transmitir rabia por lo que es necesaria la observación y PPE. Los hurones por norma deben recibir vacunación anti-rábica, la que se indica a partir de las 12 semanas de vida, siendo obligatoria su aplicación en algunos lugares de E.U.A. ${ }^{79}$. Se ha descrito infección recurrente por Mycobacterium bovis ${ }^{80}$.

Perros o marmotas de la pradera (prairie dogs). Son mascotas importadas y exportadas a través del mundo. Esta situación ha facilitado la introducción de nuevos agentes y el salto de patógenos a otras especies, con el riesgo de llegar a establecerse en los animales nativos y la portación de otros. Los perros de la pradera pueden transmitir $F$. tularensis, con un brote recientemente descrito en Texas ${ }^{81-82}$ y Yersinia pestis ${ }^{73}$. Durante mayo y junio del 2003 se describió en E.U.A. un brote de viruela del mono (monkeypox) en humanos, que fue transmitido por esta mascota ${ }^{83}$. Los animales enfermaron al entrar en contacto con roedores africanos que habían viajado de Gambia a E.U.A. En este brote se contagiaron 37 personas, incluidos los distribuidores de mascotas, amos y veterinarios. El mecanismo de transmisión fue el contacto directo con secreciones y por mordeduras. Los perros de la pradera no son reservorios naturales de esta infección pero son el mejor ejemplo de cómo se puede generar un salto de agentes patógenos entre diferentes especies, con posterior transmisión al hombre ${ }^{84-85}$. Se han descrito casos de rabia asociados a estas mascotas y reacción anafiláctica grave en humanos, secundarias a mordeduras, al igual que las producidas por hámster.

\section{Mordeduras ocasionadas por simios}

Los simios se han ido incorporando lentamente como mascotas no tradicionales; la mayoría de las mordeduras causadas por primates que están en cautiverio se relacionan con actividades de investigación, zoológicos y circos. La frecuencia de mordeduras producidas por este animal es desconocida; el año 2004 se informó de tres accidentes en Santiago de Chile, en personas relacionadas con su cuidado en zoológicos.

Estas mordeduras son una de las más dramáticas ocasionadas por animales, por el tamaño corporal del agresor y la fuerza que pueden aplicar; son más frecuentes en varones y comprometen por lo general las extremidades superiores.

El manejo inicial incluye un lavado abundante con agua o solución salina fisiológica estéril, lo más copioso posible, obtención de cultivo de la herida, considerar el riesgo de tétanos y la necesidad de profilaxis antimicrobiana, especialmente en grandes traumatismos y lesiones de mano.

Los microorganismos aislados de estas heridas son similares a lo encontrado en mordeduras humanas: Streptococcus $\alpha$-hemolíticos, Eikenella corrodens, Neisseria sp, Haemophilus parainfluenzae, Entero- 
coccus sp, anaerobios estrictos como Bacteroides sp, Fusobacterium sp y ocasionalmente enterobacterias como Escherichia coli. El tratamiento antimicrobiano debe contemplar la presencia de estos agentes; a pesar de su uso las heridas pueden complicarse de osteomielitis, tenosinovitis y contractura en flexión ${ }^{1,86}$.

Tabla 5. Profilaxis post exposición y tratamiento de infección por virus B simiano (Cercopithecine herpesvirus)

Antiviral de elección

Profilaxis post exposición

Valaciclovir $1 \mathrm{~g}$ cada 8 horas por 14 días 14 días

\section{Tratamiento de la infección}

- Sin compromiso del SNC Aciclovir $15 \mathrm{mg} / \mathrm{kg}$ cada 8 hrs e.v. o ganciclovir $5 \mathrm{mg} / \mathrm{kg}$ cada 12 hrs e.v.

- Con compromiso del SNC
En simios del Viejo Mundo, procedentes de Asia y norte del África, existe el riesgo de transmitir el virus B o Cercopithecine herpesvirus. Esta infección es endémica entre los macacos, los que se infectan por exposición de su piel o mucosas a las secreciones orales o genitales de monos infectados, la transmisión vertical en ellos es inusual. La infección es asintomática o escasamente sintomática, con lesiones orales o genitales. El virus puede permanecer en forma latente en los ganglios sensitivos y reactivarse cada cierto tiempo, con diseminación a través de la saliva, conjuntiva o secreciones genitales, lo que ocurre en condiciones de cautiverio, estrés, enfermedad o inmunosupresión. Los macacos en cautiverio con más de 2,5 años de vida son seropositivos en $100 \%$ y bajo esa edad tienen una seroprevalencia de $20 \%$. La transmisión al hombre es poco frecuente, sí se describe en personas expuestas a las secreciones de los macacos, manipulación de muestras de tejido cerebral o de LCR o que son mordidos por animales infectados. El riesgo de infección es mayor en heridas profundas difíciles de limpiar, ubicadas en cara, cuello y tórax, por la mayor facilidad que tendría el virus de ascender al SNC. El período de incubación varía de 2 días a 5 semanas (habitual entre 5 y 21 días). Se han reportado alrededor de 50 casos en humanos. Las manifestaciones clínicas de la infección por este virus son: exantema de tipo vesicular en la zona de la mordedura con linfoadenopatía proximal, aparición de parestesias de la extremidad afectada a las 3 semanas de evolución, fiebre, mialgia, dolor abdomi- nal, sinusitis y conjuntivitis, pudiendo progresar hacia el compromiso hepático y pulmonar, compromiso de SNC o periférico, o un pródromo de fiebre, calofríos y mialgias, seguido de encefalomielitis con meningismo, náuseas, vómitos, confusión, diplopía, compromiso de pares craneales y ataxia. Pueden presentarse convulsiones, hemiplejía, hemiparesia, falla respiratoria y coma. Los pacientes no tratados tienen una mortalidad de $80 \%{ }^{87-88}$. Debe hacerse énfasis en la prevención de la infección por este virus mediante educación, uso de protección ocular, mascarilla y guantes al contacto con las secreciones de los macacos o el estudio de muestras. Una vez ocurrido el accidente o mordedura se debe lavar la zona expuesta por lo menos durante 15 minutos, en el caso de afectar una mucosa, emplear solución salina fisiológica estéril y en piel, soluciones yodadas o clorhexidina. Se debe evaluar al paciente e indicar aciclovir oral o valaciclovir en el caso de lesiones con un lavado inadecuado, sospecha de infección por virus B en el macaco agresor (animal debilitado, estresado o con lesiones), en lesiones de cara, cuello y tórax, lesiones profundas y en accidentes con muestras de SNC, lesiones orales o genitales que puedan contener el virus. El esquema de profilaxis anti-viral se resume en la Tabla $5^{87}$. En nuestro país no está disponible el estudio del virus $B$.

\section{Mordeduras ocasionadas por murciélagos}

Los casos recientes de rabia en E.U.A. están asociados a variantes de virus rábico de murciélagos. Actualmente los murciélagos insectívoros son el principal reservorio del virus en nuestro país El primer murciélagos en que detectó rabia en Chile correspondía a la especie insectívora Tadarida brasiliensis. El primer caso comunicado de rabia en animales domésticos adquirido a partir de murciélagos, ocurrió el año 1985, y el último caso de rabia en humanos ocurrió en el año 1996 en la localidad de Doñihue, Sexta Región, y fue transmitido por un murciélago rabioso ${ }^{39}$.

Hay cuatro variantes genéticas descritas, involucradas en ciclos de circulación viral independiente en murciélagos en nuestro país. Los casos de rabia identificados, ya sea en animales domésticos o silvestres, han correspondido a estas variantes (Tabla 6).

Las mordeduras causadas por el murciélago son casi imperceptibles o no recordadas por los pacientes. Los murciélagos con conductas anormales, tales como volar a plena luz del día, imposibilidad para emprender el vuelo, encontrarse en lugares poco habituales como casa o jardín, etc, deben considerarse sospechosos de estar afectados por rabia. Si se encuentra un murciélago en una habitación o en el dormitorio mientras la 
persona duerme, debe realizarse profilaxis post exposición; estos animales no deben ser tocados ni tampoco debe acercarse a ellos, esta consideración es igualmente válida para las mascotas. La transmisión de rabia por aerosoles se ha reproducido en forma experimental en el laboratorio; están descritos 2 casos de rabia en los años 50 en personas que visitaron cavernas con murciélagos y uno de ellos presentaba una dermatitis crónica que pudo haber sido la puerta de entrada, este mecanismo en la actualidad es discutido ${ }^{90-91}$.

La autoridad sanitaria correspondiente debe ser notificada para la captura de estos animales. Es necesario el uso de guantes y mantenerlos tapados en cajas con abertura hacia abajo, hasta su retiro. El animal debe ser sacrificado para su estudio correspondiente.

Ante la eventualidad del contacto de una mascota con un murciélago, se debe revisar su calendario de vacunación. Si no está actualizado o es desconocido, la mascota debe ser sacrificada y estudiada; en caso de contar con inmunización vigente se indica una dosis de refuerzo y observación estricta por el dueño durante 45 días ya que, aún en estas condiciones, existe un potencial de infección ${ }^{92}$.

\section{Mordeduras ocasionadas por animales de granja}

Caballos. Los microorganismos que pueden producir infección de acuerdo a estudios publicados son: S. aureus, Neisseria sp, Pasteurella caballii, Streptococcus hyicus, Streptococcus anginosus, Actinobacillus lignieresii, B. fragilis, Bacteroides ureolytica, E. coli, Prevotella melanogenicus y Prevotella heparinolytica ${ }^{18,93}$. También puede desencadenarse una reacción anafiláctica, producida por lipocalinas, proteínas que se encuentran en altas concentraciones en la saliva de los caballos $^{94}$.

Cerdos. Se han recuperado de estas heridas Staphylococcus sp, Streptococcus milleri, Streptococcus sanguis, Streptococcus suis, difteroides, P. multocida y otras Pasteurellas, Haemophilus influenzae, Actinobacillus suis, Flavobacterium IIb like, B. fragilis $\mathrm{u}$ otros, bacilos gramnegativos anaerobios estrictos y Mycoplasma $\mathrm{sp}^{95-96}$. En estos casos debe solicitarse cultivos en medios especiales, los que serán observados por períodos prolongados. Los antibacterianos recomendados ante una herida grave son la asociación de amoxicilina/ácido clavulánico y ciprofloxacina. La infección causada por Streptococcus suis es inusual, ocasionalmente se han descrito brotes y está asociada al consumo y contacto directo con la carne de cerdo, raramente en relación al consumo de carne de jabalí. En los cerdos la infección es habitualmente asintomática pero puede manifestarse por sepsis, meningitis, artritis y neumonía. En el hombre puede producir bacteriemia, meningitis que deja como secuela una alteración auditiva en $\sim 50 \%$ de los casos, endocarditis y shock séptico con falla orgánica múltiple y muerte en $5 \%$ de los casos, ocasionalmente puede haber artritis y neumonía ${ }^{97}$. En el año 2005 se reportó un brote de infecciones por Streptococcus suis en la provincia de Sichuan, China, con más de 250 casos y una mortalidad de $20 \%$, destacando en ellos un período de incubación corto, la presencia de shock tóxico y coagulación intravascular diseminada ${ }^{98}$. Los pacientes esplenectomizados tienen mayor riesgo de desarrollar esta enfermedad. La mayoría de las infecciones son producidas por el serotipo 2, también se ha descrito casos debidos a los serotipos 4 y $14^{99}$.

Ovejas. Sus mordeduras se han relacionado a infecciones por Actinobacillus $\mathrm{sp}^{100}$.

\section{Mordeduras ocasionadas por aves}

Las lesiones por picotazos o mordeduras producidas por aves son infecciones graves. Se ha comunicado un caso de un absceso cerebral secundario

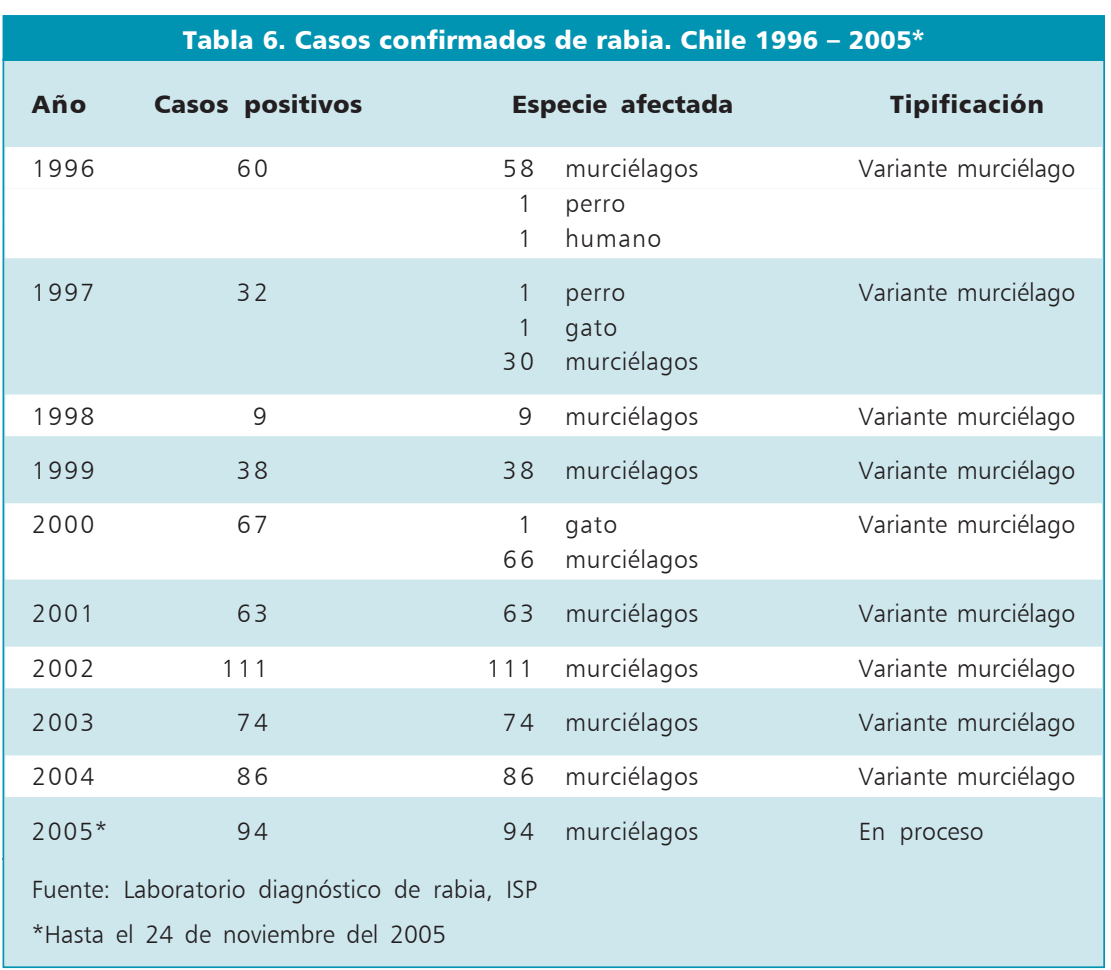


Tabla 7. Agentes transmitidos por mordeduras de animales*

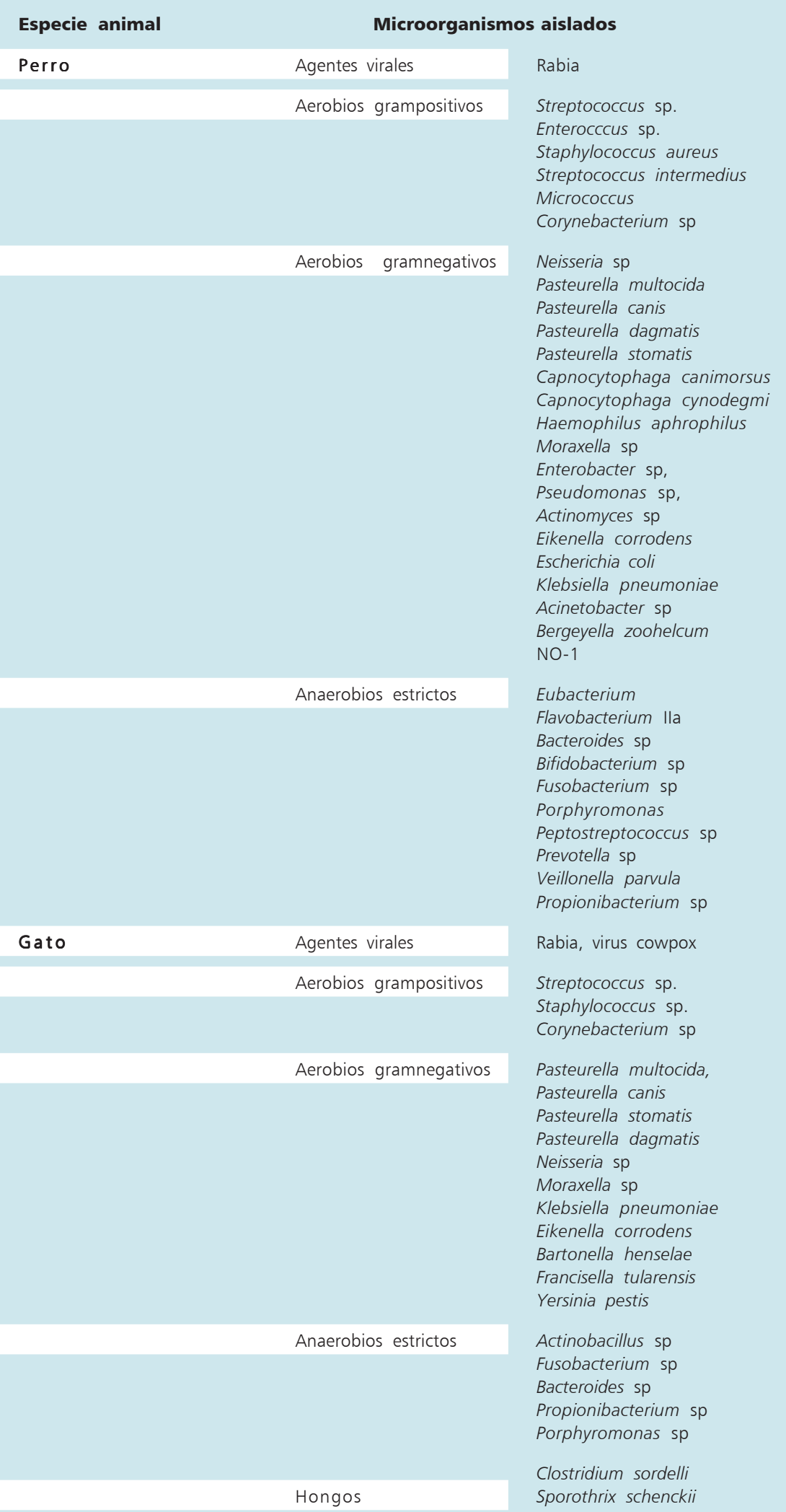

al picotazo de un gallo, en el que se aisló Streptococcus bovis, Clostridium tertium y Aspergillus niger ${ }^{101}$, y tétanos ${ }^{102}$. En agresiones producidas por lechuzas y cisnes se han descrito celulitis por Bacteroides sp y Pseudomonas aeruginosa, respectivamente ${ }^{103-104}$.

\section{Mordeduras ocasionadas por iguanas}

Los reptiles, especialmente las iguanas, son mascotas exóticas que han ido aumentando en popularidad. En E.U.A. se estima que en $\sim 3 \%$ de los hogares hay una iguana. El riesgo de salmonelosis transmitido por este agente es bien conocido ${ }^{105-106}$, en cambio el riesgo de mordedura o garrotazo es poco reportado ${ }^{107}$. Las lesiones son generalmente superficiales con abrasiones, laceraciones y heridas punzantes. Se han publicado casos de trauma facial manejados con tratamiento antibacteriano local y sistémico sin complicaciones y un caso de celulitis por Serratia marcescens ${ }^{108}$. La herida debe manejarse con irrigación, se revisará la inmunización anti-tetánica del afectado e indicará antimicrobianos profilácticos; en caso de mordedura en cara, manos, pies y en inmunocomprometidos se debe contemplar la cobertura de anaerobios estrictos y bacilos gramnegativos entéricos, por ejemplo: amoxicilina/ácido clavulánico y ciprofloxacina ${ }^{18}$. Las mordeduras ocasionadas por iguana no tienen riesgo de transmisión de rabia. Sí pueden producir reacciones alérgicas, que estarían relacionadas a la alimentación o saliva presente en la boca de estos reptiles ${ }^{109-110}$.

\section{Conclusiones}

Las mordeduras causadas por animales tienen un alto impacto en términos de consulta y tratamiento e impacto emocional sobre la víctima. Existe una importante subnotificación, la mayoría de las personas mordidas por animales no consulta en los servicios de emergencia y son manejadas en el hogar, por lo tanto es un problema subdimensionado.

El aseo local, evaluación de la extensión de la herida, revisión de la profilaxis anti-tetánica, uso de antimicrobianos profilácticos, indicados de acuerdo al tipo de herida y microbiología del animal involucrado (Tablas 7 y 8) y la vacunación anti-rábica cuando corresponda, constituyen los pilares del tratamiento. Se debe prevenir y educar especialmente a los niños y sus apoderados acerca de los riesgos asociados a estos accidentes. 


\begin{tabular}{|c|c|c|}
\hline \multirow{2}{*}{$\begin{array}{l}\text { Especie animal } \\
\text { Rata, ratón, hámster }\end{array}$} & \multicolumn{2}{|c|}{ Microorganismos aislados } \\
\hline & Agentes virales & $\begin{array}{l}\text { Virus cowpox } \\
\text { Virus de la coriomeningitis } \\
\text { linfocitaria }\end{array}$ \\
\hline & Aerobios grampositivos & $\begin{array}{l}\text { Streptobacillus moniliformis } \\
\text { Spirillum minus }\end{array}$ \\
\hline & Aerobios gramnegativos & $\begin{array}{l}\text { Pasteurella sp } \\
\text { Acinetobacter sp }\end{array}$ \\
\hline & Otros & Leptospira sp \\
\hline \multirow[t]{3}{*}{ Hurón } & Agentes virales & Rabia \\
\hline & Aerobios grampositivos & Staphylococcus aureus \\
\hline & Otros & Mycobacterium bovis \\
\hline \multirow[t]{4}{*}{ Ave } & Aerobios grampositivos & Streptococcus bovis \\
\hline & Aerobios gramnegativos & Pseudomonas aeruginosa \\
\hline & Anaerobios estrictos & $\begin{array}{l}\text { Bacteroides sp } \\
\text { Clostridium tetani }\end{array}$ \\
\hline & Hongos & Aspergillus niger \\
\hline \multirow[t]{3}{*}{ Cerdo } & Aerobios grampositivos & $\begin{array}{l}\text { Streptococcus milleri } \\
\text { Streptococcus sanguis } \\
\text { Streptoccccus suis }\end{array}$ \\
\hline & Aerobios gramnegativos & $\begin{array}{l}\text { Pasteurella sp } \\
\text { Haemophilus influenzae } \\
\text { Escherichia coli } \\
\text { Proteus sp }\end{array}$ \\
\hline & Anaerobios estrictos & $\begin{array}{l}\text { Actinobacillus suis } \\
\text { Bacteroides fragilis } \\
\text { Flavobacterium } \| \text { b }\end{array}$ \\
\hline \multirow[t]{2}{*}{ Iguana } & Aerobios grampositivos & $\begin{array}{l}\text { Streptococcus agalactiae } \\
\text { Staphylococcus sp } \\
\text { Corynebacterium sp }\end{array}$ \\
\hline & Aerobios gramnegativos & $\begin{array}{l}\text { Serratia marcescens } \\
\text { Alcaligenes sp }\end{array}$ \\
\hline \multirow[t]{3}{*}{ Caballo } & Aerobios grampositivos & $\begin{array}{l}\text { Streptococcus anginosus } \\
\text { Staphylococcus aureus } \\
\text { Staphylococcus hyicus }\end{array}$ \\
\hline & Aerobios gramnegativos & $\begin{array}{l}\text { Neisseria sp } \\
\text { Pasteurella caballii } \\
\text { Escherichia coli } \\
\text { Yersinia sp }\end{array}$ \\
\hline & Anaerobios estrictos & $\begin{array}{l}\text { Actinobacillus suis } \\
\text { Actinobacillus lignieresii } \\
\text { Bacteroides fragilis } \\
\text { Bacteroides ureolytica } \\
\text { Prevotella melaninogenicum } \\
\text { Prevotella heparinolytica }\end{array}$ \\
\hline \multicolumn{2}{|l|}{ Oveja } & Actinobacillus sp \\
\hline \multirow[t]{4}{*}{ Simio } & Virus & $\begin{array}{l}\text { Virus B simiano } \\
\text { Foamy virus }\end{array}$ \\
\hline & Aerobios grampositivos & $\begin{array}{l}\text { Streptococcus sp } \\
\text { Staphylococcus epidermidis } \\
\text { Enterococcus sp }\end{array}$ \\
\hline & Aerobios gramnegativos & $\begin{array}{l}\text { Neisseria sp } \\
\text { Eikenella corrodens } \\
\text { Enterobacteriaceas } \\
\text { Haemophilus parainfluenzae }\end{array}$ \\
\hline & Anaerobios estrictos & $\begin{array}{l}\text { Bacteroides sp } \\
\text { Fusobacterium sp }\end{array}$ \\
\hline
\end{tabular}

Tabla 8. Tratamiento antimicrobiano de elección en mordeduras, de acuerdo al tipo de animal

\section{Especie animal}

Antimicrobianos recomendados

$\begin{array}{cl}\text { Perro } & \begin{array}{l}\text { Amoxicilina/ácido clavulánico } \\ \text { Alternativas: doxiciclina, ceftriaxona } \\ \text { clindamicina más cotrimoxazol }\end{array} \\ \text { Gato } & \begin{array}{l}\text { Amoxicilina/ácido clavulánico } \\ \text { clindamicina más cotrimoxazol }\end{array} \\ \text { Ave } & \text { Amoxicilina/ácido clavulánico } \\ & \text { Considerar ciprofloxacina }\end{array}$

Hurón Cloxacilina, cefalosporinas de 10 generación

Amoxicilina/ácido clavulánico

\section{Rata, ratón}

hámster Amoxicilina/ácido clavulánico

$\begin{array}{ll}\text { Cerdo } & \text { Amoxicilina/ácido clavulánico } \\ \text { asociar ciprofloxacina }\end{array}$

$\begin{array}{ll}\text { Iguana } & \text { Amoxicilina/ácido clavulánico } \\ \text { asociar ciprofloxacina }\end{array}$

Simio Amoxicilina/ácido clavulánico

Caballo y oveja Amoxicilina/ácido clavulánico

\section{Resumen}

Las mordeduras producidas por animales domésticos, silvestres o mascotas exóticas, son un problema que no está bien dimensionado en nuestro medio; sin embargo, representan un motivo de consulta frecuente. Se revisa la epidemiología, enfrentamiento inicial y recomendaciones para el manejo de mordeduras ocasionadas por perros y gatos; por la gran importancia que han ido adquiriendo en el último tiempo se revisan las mordeduras producidas por hámsters, ratones, conejos, hurones, perros de la pradera, simios, murciélagos, aves, iguanas y animales de granja. 


\section{Referencias}

1.- Goldstein E J. Bite wounds and infection. Clin Infect Dis 1992; 14: 633-40.

2.- García V F. Animal bites and Pasteurella infection. Pediatr Rev 1997; 18: 127-30.

3.- Bernardo L M, Gardner M J, O’Dair J, Fentin N. Analysis of reports of dog bites to a health department. National Academies of Practice Forum 1999; 1: 299-303.

4.- Ibarra L, Morales M A, Acuña P. Aspectos demográficos de la población de perros $\mathrm{y}$ gatos en la ciudad de Santiago. Avances en Ciencias Veterinarias. 2003; 11: 13-21.

5.- Kahn A, Bauche P, Lamoureux J. Child victims of dog bites treated in emergency departaments: a prospective survey. Eur J Pediatr 2003; 162: 254-8.

6.- Feder H M, Shanley J D, Barbera J A. Review of 59 patients hospitalized with animal bites. Pediatr Infect Dis J 1987; 6: 24-8.

7.- Voelker R. Dog bites recognized as public health problem. JAMA 1997; 277: 278-9.

8.- Peters V, Sottiaux M, Appelboom J, Kahn A. Posttraumatic stress disorders after dog bites in children. J Pediatr 2004; 144: 121-2.

9.- Warrel M, Warrel D. Rabies and other lyssavirus diseases. Lancet 2004; 363: 95969.

10.- Lewis K, Stiles M. Management of cat and dog bites. Am Fam Physician 1995; 52: 479-89.

11.- Presutti R. Bite wounds. Early treatment and prophylaxis against infectious complications. Postgrad Med 1997; 101: 243-4.

12.- Chaudhry M A, MacNamara A F, Clark S. Is the management of dog bite wounds evidence based? A postal survey and review of the literature. Eur J Emerg Med 2004; 11: 313-7.

13.- Morgan M. Hospital management of animal and human bites. J Hosp Infect 2005; 61: 1-10.

14.- Talan D A, Citron D M, Abrahamian F M, Moran G J, Goldstein E J. Bacteriologic analysis of infected dog and cat bites. N Engl J Med 1999; 340: 85-92.

15.- Presutti R J. Prevention and treatment of dog bites. Am Fam Physician 2001; 63: 1567-72.

16.- Montejo M, Aguirrebengoa K, Ugalde J, López L, Saez Nieto J A, Hernández J L. Bergeyella zoohelcum bacteremia after a dog bite. Clin Infect Dis 2001; 33: 1608-9.

17.- Kaiser R, Garman R, Bruce M, Weyant R, Ashford D. Clinical significance and epidemiology of NO-1, an unusual bacterium associated with dog and cat bites. Emerg Infect Dis 2002; 1: 171-4.
18.- Brook I. Management of human and animal bite wounds: an overview. Adv Skin Wound Care 2005; 18: 197-203.

19.- Holts E, Rollof J, Larsson L, Nielsen J. Characterization and distribution of Pasteurella species recovered from infected humans: J Clin Microbiol 1992; 30: 2984-7.

20.- Hara H, Ochiai T, Morishima T, Arashima Y, Kumasaka K, Kawano K. Pasteurella canis osteomyelitis and cutaneous abscess after a domestic dog bite. J Am Acad Dermatol 2002; 46: S151-S152.

21.- Holm M, Tärnvik A. Hospitalization due to Pasteurella multocida- infected animal bite wounds: correlation with inadequate primary antibiotic medication. Scand J Infect Dis 2000; 32: 181-3.

22.- Pers C, Gahrn-Hansen B, Frederiksen W. Capncoytophaga canimorsus septicemia in Denmark, 1982-1995: review of 39 cases. Clin Infect Dis 1996; 23: 71-5.

23.- Sandoe J A. Capnocytophaga canimorsus endocarditis. J Med Microbiol 2004; 53: 245-8.

24.- Le Moal G, Landron C, Grollier G, Robert R, Burucoa C. Meningitis due to Capnocytophaga canimorsus after receipt of a dog bite: case report and review of the literature. Clin Infect Dis 2003; 36: e42-6.

25.- Arlet G, Sanson- Le Port M, Casin J, Ortenberg M, Perol Y. In vitro susceptibility of 96 Capnocytophaga strains, including a $\beta$-lactamase producer, to new $\beta$-lactam antibiotics and six quinolones. Antimicrob Agents Chemother 1987; 31: 1283-4.

26.- Khawari A A, Myers J M, Ferguson D A, Moorman J P. Sepsis and meningitis due to Capnocytophaga cynodegmi after splenectomy. Clin Infect Dis 2005; 40: 1709-10.

27.- Reina J, Bornell N. Leg abscess caused by Weeksella zoohelcum following a dog bite. Clin Infect Dis 1992; 14: 1162-3.

28.- Hollis D, Moss C, Daneshvar M, Meadows L, Jordan J, Hill B. Characterization of Centers for Disease Control group NO-1, a fastidious, non oxidative, gram negative organism associated with dog and cat bites. J Clin Microbiol 1993; 31: 746-8.

29.- Kaiser R M, Garman R L, Bruce M G, Weyant R S, Ashford D A. Clinical significance and epidemiology of NO-1, and unusual bacterium associated with dog and cat bites. Emerg Infect Dis 2002; 8: 171-4.

30.- Panagea S, Bijoux R, Corkill J E, Al Rashidi F, Hart C A. A case of lower respiratory tract infection caused by Neisseria weaveri and review of the literature. J Infect 2002; 44: 96-8.
31.- Andersen B M, Steigerwaldt A G, O'Connor S P, Hollis D G, Weyant R S, Weaver R E et al. Neisseria weaveri sp nov formerly CDC group M-5, a gram negative bacterium associated with dog bite wounds. J Clin Microbiol 1993; 31: 2456-66.

32.- Allison K, Clarridge J E 3rd. Long term respiratory tract infection with canine associated Pastereulla dagmatis and Neissseria canis in a patient with chronic bronchiectasis. J Clin Microbiol 2005; 43: 4274-4.

33.- Cummings P. Antibiotics to prevent infection in patients with dog bite wound: meta-analysis of randomized trials. Ann Emerg Med 1994; 23: 535-40.

34.- Medeiros I, Sacconato H. Antibiotic prophylaxis for mammalian bites (Cochrane Review). Cochrane Library Volume 4, 2004

35.- Anderson C. Animal bites. Guidelines to current management. Postgrad Med 1992; 92: $134-6$

36.- Morgan M. Prophylaxis should be considered even for trivial animal bites. $\mathrm{Br}$ Med J 1997; 314: 1413.

37.- Fleisher G. The management of bite wounds. N Engl J Med 1999; 340: 138-40.

38.- Favi M, Catalán R. Rabia en murciélagos en Chile. Avances en Ciencias Veterinarias 1986; 1: 73-6.

39.- Favi M, De Mattos C A, Yung V, Chala E, López L R, De Mattos C C. First case of human rabies in Chile caused by an insectivorous bat virus variant. Emerg Infect Dis 2002; 8: 79-81.

40.- Hankins D G, Rosekrans J. Overview, prevention and treatment of rabies. Mayo Clin Proc 2004; 79: 671-6.

41.- Rupprecht C E, Gibbons R V. Prophylaxis against rabies. N Engl J Med 2004; 351: 2626-35.

42.- Rupprecht C E, Hanlon C A, Hemachudha T. Rabies re-examined. Lancet Infect Dis 2002; 2: 327-43.

43.- Iazetti L. Anticipatory guidance: having a dog in the family. J Pediatr Health Care 1998; 12: 73-9.

44.- Kravetz J D, Federman D G. Cat-associated zoonoses. Arch Intern Med 2002; 162: 1945-52.

45.- Montes C, Acevedo C, Mora M, Salinas H, Fica A. Artritis séptica y celulitis por Pastereulla multocida secundaria a mordedura de gato. Rev Chil Infect 1997; 14: $173-6$

46.- Westling K, Bygdeman S, Engkvist O, Jorup-Rönström C. Pasteurella multocida infection following cat bite in humans. J Infect 2000; 40: 97-103.

47.- Valtonen M, Lauhio A, Carlson P, Multanen J, Sivonen A, Vaara $\mathrm{M}$ et al. 
Capnocytophaga canimorsus septicemia: fifth report of a cat-associated infection and five other cases. Eur J Clin Microbiol 1995; 14: 520-3.

48.- La V D, Clavel B, Lepetz S, Aboudharam G, Paoult D, Drancort M. Molecular detection of Bartonella henselae DNA in the dental pulp of 800 year old French cats. Clin Infect Dis 2004; 39: 1391-4.

49.- Shaw S E, Kenny M J, Tasker S, Birtles R J. Pathogen carriage by the cat flea Ctenocephalides felis (Bouché) in the United Kingdom. Vet Microbiol 2004; 102: 183-8.

50.- Bass J W, Vincent J M, Person D A. The expanding spectrum of Bartonella infections: II. Cat scratch disease. Pediatr Infect Dis J 1997; 16: 163-79.

51.- Capellan J, Fong I W. Tularemia from a cat bite: case report and review of felineassociated tularemia. Clin Infect Dis 1993; 16: $472-5$.

52.- Gage K L, Dennis D T, Orloski K A, Ettestad P, Brown T L, Reynolds P J, et al. Cases of cat-associated human plague in the Western US, 1977-1998. Clin Infect Dis 2000; 30: 893-900.

53.- Capitini C M, Herrera I A, Patel R, Ishitani M B, Boyce T G. Wound infection with Neisseria weaveri and a novel subspecies of Pasteurella multocida in a child who sustained a tiger bite. Clin Infect Dis 2002; 34: e74-6.

54.- Knobel Freud H, López Colomes J L, Serrano Sainz C, Hernández Vidal P. Animal bites. Study of 606 cases. Rev Clin Esp 1997; 197: 560-3.

55.- Martin R W, Martin D L, Levy C S. Acinetobacter osteomyelitis from a hamster bite. Pediatr Infect Dis J 1988; 7: 364-5.

56.- Freeman A F, Zheng X T, Lane J C, Shulman S T. Pasteurella aerogenes hamster bite peritonitis. Pediatr Infect Dis J 2004; 23: 368-70.

57.- Campos A, Taylor J H, Campbell M. Hamster bite peritonitis: Pasteurella pneumotropica peritonitis in a dyalisis patient. Pediatr Nephrol 2000; 15: 31-2.

58.- Barton L L, Mets M B. Congenital lymphocytic choriomeningitis virus infection: decade of rediscovery. Clin Infect Dis 2001; 33: 370-4

59.- Barton L L, Mets M B, Beauchamp C L. Lymphocytic choriomeningitis virus: emerging fetal teratogen. Am J Obstet Gynecol 2002; 187: 1715-6.

60.- Riera L, Castillo E, Saavedra M C, Priotto J, Sottosanti J, Polop J et al. Serological study of the lymphochoriomeningitis virus (LCMV) in an inner city of Argentina. J Med Virol 2005; 76: 285-9.
61.- Barton L, Mets M B. Lymphocytic choriomeningitis virus: pediatric pathogen and fetal teratogen. Pediatr Infect Dis J 1999; 18: 540-1.

62.- Interim guidance for mimizing risk for human lymphocytic choriomeningitis virus infection with rodents. MMWR Morb Mortal Wkly Rep 2005; 54: 747-9.

63.- Lim D L, Chan R M, Wen H, Van Bever H P, Chua K Y. Anaphylaxis after hamster bites- identification of a novel allergen. Clin Exp Allergy 2004; 34: 1122-3.

64.- Tomitaka A, Suzuki K, Akamatsu H, Matsunaga K. Anaphylaxis after hamster bites: a rare cases?. Contact Dermatitis 2002; 46: 113 .

65.- Hirschhorn R B, Hodge R R. Identification of risk factors in rat bite incidents involving humans. Pediatrics 1999; 104: e35.

66.- Torres F, Navarrete J, Aldunate R, Yates T L, Mertz G J, Vial P A et al. Peridomestic small mammals associated with confirmed cases of human hantavirus disease in South Central Chile. Am J Trop Med Hyg 2004; 70: 305-9.

67.- Heyman P, Plyusnina A, Berny P, Cochez C, Artois M, Zizi M et al. Seoul hantavirus in Europe: first demonstration of the virus genome in wild Rattus norvegicus captured in France. Eur J Clin Microbiol Infect Dis 2004; 23: 711-7.

68.- Gilroy S A, Khan M U. Rat bite fever: case report and review of the literature. Infect Dis Clin Practice 2002; 11: 403-5.

69.- Legout L, Sennerville E, Mulleman D, Solono Gervais E, Filipo RM, Mouton Y. Rat bite fever mimicking rheumatoid arthritis. Scand J infect Dis 2005; 37: 532 3.

70.- Anonymous. Fatal rat bite fever-Florida and Washington 2003. MMWR Morb Mortal Wkly Rep 2005; 53: 1198-2002.

71.- Valverde C, Lowenstine L, Young C E, Tarara R P, Roberts J A. Spontaneous rat bite fever in non- human primates: a review of two cases. J Med Primatol 2002; 31: 345-9.

72.- Wallet F, Savage C, Loïez C, Renaux E, Pischedda P, Courcol RJ. Molecular diagnosis of arthritis due to Streptobacillus moniliformis. Diag Microbiol Infect Dis 2003; 47: 623-4.

73.- Chomel B B. Zoonoses of house pets other than dogs, cats and birds. Pediatr Infect Dis J 1992; 11: 479-87.

74.- Centers for Diseases Control and Prevention: Human rabies prevention: United States, 1999: Recommendations of the Advisory Committee on Immunization Practices (ACIP). MMWR Morb Mortal Wkly Rep 1999: 48: 1-21.
75.- Wyatt J P. Squirrel bite. Br Med J 1994; 309: 1694.

76.- Zar F A. Lymphocutaneous sporotrichosis associated with a squirrel bite: case report and review. Clin Infect Dis 1996; 23: 647-8.

77.- $\quad$ Magee J S, Steele R W, Kelly N R, Jacobs R F. Tularemia transmitted by a squirrel bite. Pediatr Infect Dis J 1989; 8: 123-5.

78.- Morrison G. Zoonotic infections from pets. Understanding the risks and treatment. Postgrad Med 2001; 110: 24-48.

79.- Applegate J A, Walhout M F. Childhood risks from the ferret. J Emerg Med 1998; 16: 425-7.

80.- Jones J W, Pether J V, Rainey H A, Swinburn C R. Recurrent Mycobacterium bovis infection following a ferret bite. J Infect 1993; 26: 225-6.

81.- Avashia S B, Petersen J M, Lindley C M, Schriefer M E, Gage K L, Cetron M, et al. First reported prairie dog- to- human tularemia transmission, Texas, 2002. Emerg Infect Dis 2004; 10: 483-5

82.- Alcalá P J, Fernández A, Sánchez A, Loeda C. Infección por Francisella tularensis transmitida por un perro de las praderas. An Pediatr (Barc) 2004; 60: 583-4.

83.- Reed K D, Melski J W, Graham M B, Regnery R L, Sotir M J, Wegner M V. The detection of monkeypox in humans in the western hemisphere. N Eng J Med 2004; 350: $342-50$.

84.- Guarner J, Johnson B J, Paddock C D, Shieh W J, Goldsmith C S, Reynolds M G et al. Monkeypox transmission and pathogenesis in prairie dogs. Emerg Infect Dis 2004; 10: 426-31.

85.- Azad A F. Prairie dog: cuddly pet or Trojan horse? Emerg Infect Dis 2004; 10: 542-3.

86.- Goldstein E J, Pryor E P 3rd, Citron D M. Simian bites and bacterial infection. Clin Infect Dis 1995; 20: 1551-2.

87.- Engel G A, Engel L J, Schillaci M A, Suaryana K G, Putra A, Fuentes A et al. Human exposure to herpesvirus Bseropositive Macaques, Bali, Indonesia. Emerg Infect Dis 2002; 8: 789-95.

88.- Huff JL, Barry PA. B-virus (Cercopithecine herpesvirus 1) infection in humans and macaques: potential for zoonotic disease. Emerg Infect Dis 2003; 9: 246-50.

89.- Cohen J I, Davenport D S, Stewart J A, Deitchman S, Hilliard J K, Chapman L E. Recommendations for prevention of and therapy for exposure to B virus (Cercopithecine herpesvirus 1). Clin Infect Dis 2002; 35: 1191-203.

90.- Gibbons R V. Cryptogenic rabies, bats and the question of aerosol transmission. Ann Emerg Med 2002; 39: 528-36.

91.- Jackson A C, Fenton M B. Human rabies and bat bites. Lancet 2001; 357: 1714. 
92.- Compendium of animal rabies prevention and control, 2004. National Association of State Public Health Veterinarians, Inc (NASPHV). MMWR Morb Mortal Wkly Rep 2004; 53: RR-9: 1-9.

93.- Toovey S, Annandale Z, Jamieson A, Schoeman J. Zebra bite to a South tourist. J Travel Med 2004; 11: 122-4.

94.- Rolla G. Anaphylaxis after a horse bite. Allergy 2005; 60: 1088-9.

95.- Morgan M S. Treatment of pig bites. Lancet 1996; 348: 1246.

96.- Escande F, Bailly A, Bone S, Lemozy J. Actinobacillus suis infection after a pig bite. Lancet 1996; 348: 888.

97.- Huang Y T, Teng L J, Ho S W, Hsueh P R. Streptococcus suis infection. J Microbiol Immunol Infect 2005; 38: 306-13.

98.- World Health Organization. Outbreak associated with Streptococcus suis in pigs, China. Wkly Epidemiol Rec 2005; 80: 269-70.
99.- Lopreto C, Lopardo H A, Bardi M C, Gottschalk M. Primary Streptococcus suis meningitis: first case described in Latin America. Enferm Infecc Microbiol Clin 2005: 23: 1140.

100.- Peel M M, Hornidge K A, Luppino M. Actinobacillus sp and related infections in infected wounds of human bitten by horses and sheep. J Clin Microbiol 1991; 29: 2535-8.

101.- Berkowitz F E, Jacobs D W. Fatal case of brain abscess caused by rooster pecking. Pediatr Infect Dis J 1987; 6: 941-2.

102.- Kara C O, Cetin C B. Cephalic tetanus as a result of rooster pecking: an unusual case. Scand J Infect Dis 2002; 34: 64-6.

103.- Davis B, Wenzel R P. Striges scalp: Bacteroides infection after an owl attack. J Infect Dis 1992; 165: 975-6.

104.- Ebrey R J, Hayek L J. Antibiotic prophylaxis after a swan bite. Lancet 1997; 350: 340 .
105.- Dalton C, Hoffman R, Pape J. Iguana associated salmonellosis in children. Pediatr Infect Dis J 1995; 14: 319-20.

106.- Mermin J, Hoar B, Angulo F J. Iguanas and Salmonella marina infection in children: a reflection of the increasing incidence of reptile-associated salmonellosis in the United States. Pediatrics 1997; 99: 399 402.

107.- Bibbs C S, Willis F B, Bartton R L. Iguana bites to the face. J Am Board Fam Pract 2001; 14: 152-4.

108.- Hsieh S, Babl F E. Serratia marcescens cellulitis following an iguana bite. Clin Infect Dis 1999; 28: 1181-2.

109.- Levine E G, Manilov A, Maclister S C, Heymann WR. Iguana bite induced hypersensivity reaction. Arch Dermatol 2003; 139: 1658-9.

110.- Kelso J M, Fox R W, Jones R T, Yunginger J V. Allergy to iguana. J Allergy Clin Immunol 2000; 106: 369-72. 